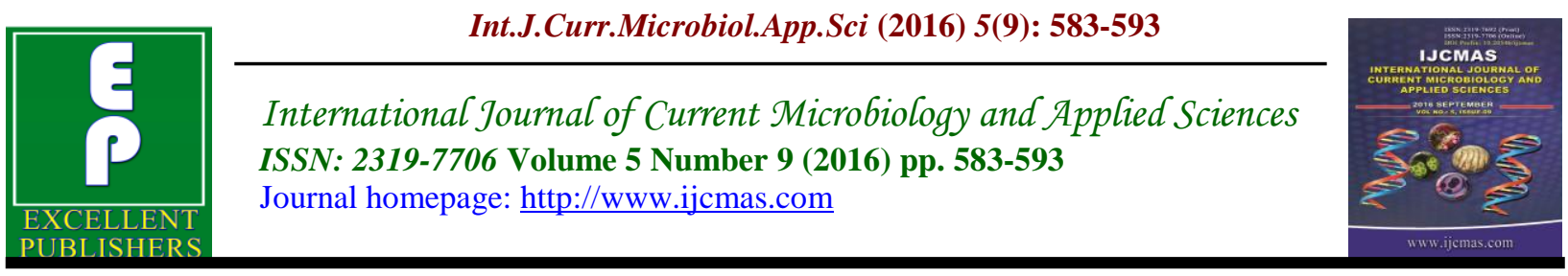

Original Research Article

http://dx.doi.org/10.20546/ijcmas.2016.509.066

\title{
Isolation and Characterization of PGPR from Roots of Ficus religiosa growing on Concrete Walls and its Effect on Plant Growth in Drought Condition
}

\author{
Seema P. Rodge, Sayali K. Sable, Shraddha K. Salve, \\ Sujata A. Sawant and Niranjan Prakashrao Patil* \\ Department of Microbiology, Abasaheb Garware College, Pune, Maharashtra, India \\ *Corresponding author
}

A B S T R A C T

Keywords

PGPR, Ficus

religiosa,

drought tolerant,

ACC deaminase,

multifunctional

PGPR.

Article Info

Accepted:

20 August 2016

Available Online:

10 September 2016
Plant growth promoting rhizobacteria (PGPR) are natural soil bacteria inhabiting rhizosphere, rhizoplane and roots of plants, promoting plant growth by a variety of direct and indirect mechanisms. Ficus religiosa growing on concrete walls or rocks experience stress conditions, hence we hypothesize that rhizobacteria of such a plant may have potential to support plant growth in adverse conditions. 30 root samples of Ficus religiosa were processed and screened for isolation of PGPR and 48 different bacteria were isolated. These isolates were characterized for their multifunctional ability to produce plant growth hormones like IAA, siderophores production, solubilisation of Zinc, potash and phosphate. Antagonistic activity was checked as HCN production ability. Furthermore isolates were assessed for 1aminocyclopropane-1-carboxylic acid (ACC) deaminase enzyme production. Out of 48 isolates, 10 isolates (consortium RL) were selected for seed germination and root shoot elongation assay. The ability of rhizobacteria to support plant growth in drought condition was checked in plate test by applying water stress condition. The results indicated that rhizobacteria from Ficus religiosa significantly enhanced root and shoot length compared to control under water stress condition.

\section{Introduction}

The world is facing problems of overpopulation, industrialization,

urbanization, food scarcity and drought, implying major challenges for the agriculture sector to secure food availability to mankind. Hence, increasing the crop yield from available land and water is the only alternative left with us. Plants are often challenged by several environmental stresses due to climatic changes which negatively affect the plant growth and productivity
(Gao et al., 2007). Lichtenthaler (1998) defines the term stress as any un-favorable condition or substance that affects or blocks a plant's metabolism or growth, which can be induced by various natural factors. Stress includes two types of stress i.e biotic and abiotic. Biotic stress involves interference from humans and animals, variety of pathogenic microorganisms whereas, abiotic stress involves water logging, drought, heat, cold, wind, intense light, water salinity etc 
(Vinocur and Altman 2005; Wahid et al., 2007).The agriculturist demand sustainable solution to combat climatic changes affecting crop yield. In this paper we evaluate rhizobacteria isolated from the roots of Ficus religiosa plant for their beneficial traits on maize seed germination and growth. Plant growth promoting rhizobacteria (PGPR) are heterogeneous group of naturally occurring soil bacteria that colonize plant roots and benefit plants by providing growth promotion directly or indirectly. (Agrawal and Agrawal, 2013). PGPR are known for their ability to induce plant defence/tolerance and antagonize plant pathogens. PGPR are considered as potential biocontrol agents which promotes plant growth (Planchamp et al., 2014; Barriuso et al., 2008). Use of PGPR is a promising solution for sustainable, environmental friendly agriculture and has gained worldwide importance and accept ance for agricultural benefits.

PGPR can enhance plant growth directly by providing plants with nutrients such as nitrogen through the process of nitrogen fixation or by solubilizing phosphorus from soil bound phosphate (Zaidi et al., 2009; Berg, 2009). PGPR also have ability to synthesize several plant growth hormones such as auxins and cytokinins (Berg, 2009; Yang et al., 2009). PGPR can modulate levels of the plant stress hormone 'ethylene' by producing 1-aminocyclopropane-1carboxylate (ACC) deaminase enzyme by metabolizing ACC into a-ketobutyrate and ammonia (Glick, 2014). Recently, rhizobacteria having ACC deaminase activity were recommended as solution to relieve stress on crop plants. PGPR also forms biofilms which are mainly composed of bacteria and extracellular matrix and several classes of sugars that plays role improving plant abiotic stress tolerance via maintaining water availability in the rhizosphere (Yang et al., 2009; Dimkpa et al., 2009). However, till date limited scientific efforts were taken to explore the available microbial diversity for its exploitation in agriculture. Ficus religiosa (Moraceae) is the most popular member of the genus Ficus, commonly named as Peepal (India) and is claimed to have long life. In urban India this plant is commonly found to grow in crevices of concrete walls with limited resources. We hypothesize that a exceptional ability of plant to survive and grow under rigorous condition may be due to considerable plant roots association with rhizobacteria. In our opinion rhizobacteria of Ficus religiosa may offer benefit to crop plants to survive and grow under stress condition.

In the present study root samples from concrete walls and pavements of Ficus religiosa plant were collected from Pune city for assessment of PGPR. The main objectives of this study are to isolate and characterize PGPR from the rhizoplane of Ficus religiosa, and to screen their abilities of direct and indirect plant growth promotion in drought conditions. The in vitro evaluation of selected PGPR on seeds of crop plant was performed

\section{Materials and Methods}

\section{Sampling and Isolation of PGPR}

Samples were collected from different locations in Pune city (Maharashtra, India). Roots of Ficus religiosa growing on concrete walls and pavements were collected in sterile plastic bags. Collected roots were washed twice with sterile distilled water and suspended in sterile saline.

Serial dilutions were performed and suspensions were plated (spread plate) on on 
nutrient agar medium and incubated at room temperature for 24 hours. Isolated colonies having dissimilar morphology were streaked on Nutrient Agar medium to know purity of isolate. The pure cultures were preserved on nutrient agar slants. The maize (Zea mays) seeds were purchased from local market.

\section{Screening of PGPR traits}

The isolates were evaluated for following plant growth promoting traits.

\section{Indole acetic acid production}

Indole acetic acid (IAA) production was detected as described by Brick et al., (1991). $1 \%$ tryptone water broth was inoculated with loop full of bacterial suspension and incubated for 48 hours at $30 \pm 2^{\circ} \mathrm{C}$. The broth was centrifuged at $10000 \mathrm{rpm}$ for $10 \mathrm{~min}$ and supernatant was mixed with equal volume of Salkowaskya's reagent. After for 30 min in dark development of pink colour indicates IAA production.

\section{Siderophore production}

Siderophore production was detected by Chrome azural S (CAS) method (Schwyn and Neilands, 1987). For detection of siderophore, bacterial isolates were spot inoculated on King's B agar medium containing CAS reagent and incubated for 72 hours. Positive results were indicated by development of orange halo around the bacterial colony after incubation for $48 \mathrm{hrs}$ at room temperature.

\section{Nitrogen fixation}

Isolates were streaked on sterile Ashby's mannitol nitrogen free agar medium and incubated at room temperature for 48 hours. Growth on Ashby's agar medium indicates Nitrogen fixing atmospheric ability.

\section{HCN production}

The isolates were screened for the productions of hydrogen cyanide by adopting the slight modification of method of Castric (1975). Nutrient agar was amended with glycine $(4.4 \mathrm{~g} / \mathrm{L})$ and cultures were streaked on this modified agar slants in screw capped tubes. A Whatman Filter paper no. 1 strip soaked in $2 \%$ Sodium carbonate in $0.5 \%$ picric acid was placed on the top of the tube and was tightly capped. Tubes were incubated for 48 hours $30 \pm 2^{\circ} \mathrm{C}$. Development of orange to red color on paper indicates $\mathrm{HCN}$ production.

\section{Phosphate solubilization}

The culture suspension was spot inoculated on Pikovskya's medium (having insoluble Tri-calcium phosphate as sole source of phosphate) and plates were incubated on room temperature for 36 to 72 hours. Clear zone around the microbial colony indicates phosphate solubilizing ability of bacteria (Bharucha et al., 2013).

\section{Zinc solubilization}

The suspension of isolate was spot inoculated on medium containing dextrose (1 $\mathrm{g} \%$ ), ammonium sulphate $(0.1 \mathrm{~g} \%)$, potassium chloride $(0.02 \mathrm{~g} \%)$, di-potassium phosphate $(0.01 \mathrm{~g} \%)$, magnesium sulphate $(0.02 \mathrm{~g} \%)$, zinc oxide $(0.1 \mathrm{~g} \%)$ and agar (3 $\mathrm{g} \%)$. Clear zone around the bacterial colony indicates zinc solubilizing ability of bacteria (Goteti et al., 2013).

\section{Potash solubilization}

Aleksandrov's agar medium (1\% mica powder) was spot inoculated by culture suspension and plates were incubated on room temperature for 36 to 72 hours. The zone of clearance around the colony indicated potash solubilizing ability of bacteria (Parmar and Sindhu, 2013). 


\section{Ammonia production}

18 hours old culture was inoculated in $10 \mathrm{ml}$ of $1 \%$ peptone broth and incubated at room temperature on shaker $(120 \mathrm{rpm})$ for 48 hours. $0.5 \mathrm{ml}$ of Nessler's reagent was added in each tube, development of faint yellow to dark brown color indicated production of ammonia (Cappuccino and Sherman, 1992).

\section{ACC Deaminase production}

Qualitative analysis of ACC deaminase activity was performed as previously described by Penrose and Glick (2003) by measuring the amount of $\alpha$-ketobutyrate produced when ACC deaminase cleaves ACC into $\alpha$-ketobutyrate and water.

\section{Characterization of isolates}

The taxonomic features of selected isolates were determined using routine morphological (colonial, Gram, motility, spore staining) and biochemical (catalase, oxidase, nitrate) criteria.

\section{Seed germination experiment}

Maize (Zea mays) seed germination assay was done by applying consortium-RL of 10 cultures. The cultures were grown in sterile nutrient broths up to $1.0 \mathrm{OD}$ at $530 \mathrm{~nm}$. The consortium-RL of 10 isolate was prepared by mixing each culture equally having 1.0 $\mathrm{OD}$ at $530 \mathrm{~nm}$. Seeds were surface sterilized with $0.1 \% \mathrm{HgCl}_{2}$ for $3 \mathrm{~min}$ and washing with distilled water for 6 times. 30 surface sterilized seeds of maize were bacterized with inoculums for $30 \mathrm{~min}$. The seeds were then transferred on moist sterilized filter paper in Petri plates and were incubated at room temperature and left undisrupted. Seeds soaked in sterile distilled water were used as negative control. experiments were performed in triplicates. The specified distilled water addition was followed every day until $7^{\text {th }}$ day as shown in Figure 1. The root and shoot lengths were measured and statistical analysis was done using independent sample $\mathrm{t}$ test to know significant difference between treated and control. The observations were considered significant when $\mathrm{P}$ was $\leq 0.05$.

\section{Results and Discussion}

\section{Isolation and Selection of PGPR isolate}

The total 22 root samples of Ficus religiosa growing on concrete walls and pavement were collected from different locations of Pune. A total 48 pure bacterial isolates were obtained from collected samples. The 48 isolates were qualitatively assessed for 9 different multifarious activities. The isolates having maximum number of PGPR traits were selected for further studies. 10 isolate were exhibiting maximum number of traits. The selected 10 isolate also show variation in morphological characters, biochemical characters and colony morphology. The goal of determining taxonomic character was to ensure that isolates of different types represent the consortium-RL. Nonetheless, the identification of isolates up to species level will be followed depending on its potential in promoting growth and productivity. Cronobacter malonaticus BR1 was reported as one of potential isolate from Ficus religiosa by Bhatt et al.(2014). Nimnoj and Pongslip(2009) reported 72 indole acetic acid producing isolate from Ficus religiosa L., Leucaena leucocephala and Piper sarmentosum Roxb. The radiation resistant bacteria, Deinococcus ficus sp. nov., isolated from the rhizosphere of Ficus religiosa L (Lai et al., 2006).On this background, our study focuses extensively on rhizobacteria from Ficus religiosa. 


\section{PGPR traits}

It was assumed initially that some soil bacteria fix atmospheric $\mathrm{N}_{2}$ and increase crop yield. Subsequently, it became clear that these rhizobacteria enhance root and shoot lengths by variety of mechanisms like phytoharmone production, enhanced nutrient availability, enhanced stress tolerance, pathogen suppression and enhanced nutrient uptake. The search for ideal multifarious (having all the traits) bacteria non-specific for host plant is the necessity of sustainable agriculture practice. The outcome of present research work is 10 different PGPR isolates having minimum 5 and maximum 8 PGPR traits out of nine traits evaluated as shown in Table 1.IAA is one of the most important phytohormone and function as important signal molecule in regulation of plant development. In our study all of the selected bacterial isolates were positive for IAA production (Figure 2a). Another important trait of PGPR is ammonia production that indirectly influences the plant growth (Ajay Kumar, 2011). HCN is secondary metabolite produced by various bacteria, and it acts as antagonist on plant pathogens thus helps promoting plant growth (Karmel Reetha, 2014). In present study, only 3 isolates were positive for $\mathrm{HCN}$ production which acts as inducer of plant resistance and SMJ2II showed fastest reaction (Figure 2b). Siderophore, a iron chelator was also produced by eight bacterial isolates in which T6 showed highest siderophore production on CAS agar plate. Five isolates were found to utilize ACC and produce alpha ketobutyrate, which was detected using 2, 4 dinitro phenyl hydrazine reagent. This byproduct is as a result of cultures producing ACC deaminase enzyme which utilizes
ACC as a sole source of nitrogen. Out of 10 isolates, isolate T6 showed high ACC deaminase activity(Figure 2c). All isolates were able to produce ammonia. The isolate SMJ2II and T6 shown maximum eight trait out of nine PGPR trait. The isolate SMJ2II is ACC deaminase negative and isolate T6 do not solubilize insoluble phosphate. Similar finding of multiple activities from rhizospheres of various plant were reported (Bhatt et al., 2014; Joseph et al., 2007; Kloepper and Schrot, 1978). Our results include more activities reported per isolate. The rhizosphere involves complex dynamic interaction of plant and microbes influenced by physicochemical environment around. Theoretically, isolate having multiple traits has more chance to confer plant growth promotion effecting increased crop yield.

\section{Identification of selected Isolates}

The identification of bacterial isolate to species level is necessary to know taxonomic identity, but at this level our requirement is to avoid replication in the members of consortium-RL. The ten isolates were fully differentiated based on taxonomic criteria as given in Table 2 and PGPR traits in Table 1.

\section{Maize seed assay}

The consortium was chosen over pure culture as it manipulates synergistically various situation efficiently compare to pure isolate. The consortium-RL treated seed showed average $90 \%$ germination compare to $73 \%$ germination in $\mathrm{D} / \mathrm{W}$ treated seed. The data from Table 3 revealed that consortium-RL treatment promotes maize seed germination and root shoot elongation. 
Table.1 Multiple PGPR activities of strains isolated from rhizosphere of Ficus religiosa

\begin{tabular}{|c|c|c|c|c|c|c|c|c|c|}
\hline \multirow[b]{2}{*}{$\frac{\stackrel{0}{\sigma}}{\stackrel{0}{0}}$} & \multirow{2}{*}{ 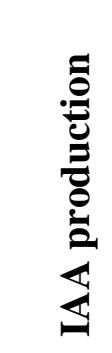 } & \multirow[b]{2}{*}{ 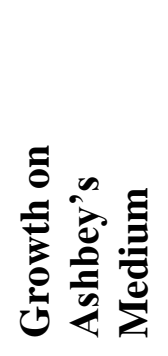 } & \multirow[b]{2}{*}{ 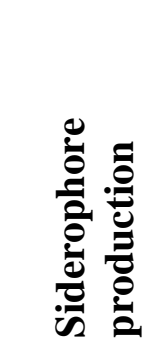 } & \multirow{2}{*}{ 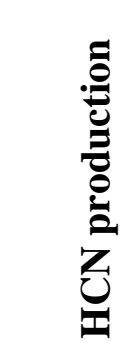 } & \multicolumn{3}{|c|}{ Solubilization } & \multirow[b]{2}{*}{ 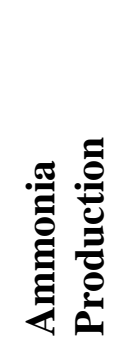 } & \multirow{2}{*}{ 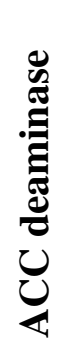 } \\
\hline & & & & & 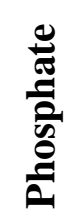 & $\stackrel{\Xi}{\tilde{N}}$ & $\begin{array}{l}\frac{\pi}{5} \\
\frac{5}{0} \\
2\end{array}$ & & \\
\hline SMJ 2 I & + & - & + & - & - & + & + & + & + \\
\hline $\begin{array}{l}\text { SMJ } 2 \\
\text { II }\end{array}$ & + & + & + & + & + & + & + & + & - \\
\hline T2 & + & + & + & - & - & - & - & + & + \\
\hline T6 & + & + & + & + & - & + & + & + & + \\
\hline T8 & + & + & - & - & + & + & + & + & + \\
\hline FC2 & + & + & + & - & - & + & + & + & - \\
\hline B1 I & + & - & + & + & - & + & - & + & - \\
\hline YB1 & + & + & + & - & - & + & + & + & - \\
\hline $\mathrm{C1}$ & + & + & - & - & - & + & + & + & + \\
\hline $\mathrm{C2}$ & + & + & + & - & - & + & + & + & - \\
\hline
\end{tabular}

$+=$ activity detected, $-=$ activity not detected

Table.2 Taxonomic characterization of selected strains isolated from rhizosphere of Ficus religiosa.

\begin{tabular}{|l|l|l|l|l|l|l|}
\hline $\begin{array}{l}\text { Isolate } \\
\text { code }\end{array}$ & Gram character and shape & Motility & Catalase & Oxidase & Nitrate & $\begin{array}{l}\text { Spore } \\
\text { staining }\end{array}$ \\
\hline SMJ 2 I & Gram positive Short rods & + & + & + & + & + \\
\hline SMJ 2 II & Gram positive rods & - & + & + & + & - \\
\hline T2 & Gram positive cocco-bacilli & - & + & + & - & + \\
\hline T6 & Gram positive rods & - & + & - & + & - \\
\hline T8 & Gram positive Rods & + & + & - & + & - \\
\hline FC2 & Gram positive cocci & - & + & - & - & - \\
\hline B1 I & Gram positive cocci & - & + & + & - & - \\
\hline YB1 & Gram positive cocci & + & + & - & + & - \\
\hline C1 & Gram positive cocci & - & + & - & + & - \\
\hline C2 & Gram positive cocci & - & + & + & - & - \\
\hline
\end{tabular}


Table.3 Effect of variable water addition on root and shoot elongation of maize seed after 7 days of incubation

\begin{tabular}{|l|l|l|l|l|}
\hline $\begin{array}{l}\text { Water } \\
\text { Added per } \\
\text { day }(\mathrm{ml})\end{array}$ & \multicolumn{2}{|l|}{ Root length $(\mathrm{cm})$} & \multicolumn{2}{l|}{ Shoot length $(\mathrm{cm})$} \\
\hline & Control & Consortium-RL & Control & Consortium-RL \\
\hline 5 & $5.78 \pm 1.87$ & $10.63 \pm 2.76$ & $3.91 \pm 1.33$ & $5.48 \pm 1.64$ \\
\hline 4 & $5.54 \pm 1.31$ & $10 . .48 \pm 2.11$ & $3.12 \pm 1.37$ & $5.12 \pm 1.59$ \\
\hline 3 & $4.21 \pm 1.09$ & $9.54 \pm 1.86$ & $2.78 \pm 1.21$ & $4.97 \pm 1.24$ \\
\hline 2 & $3.18 \pm 0.92$ & $8.03 \pm 1.34$ & $1.02 \pm 0.93$ & $3.09 \pm 1.01$ \\
\hline 1 & NG & NG & NG & NG \\
\hline
\end{tabular}

Mean length \pm standard deviation, $\mathrm{NG}=$ No germination of seed

Fig.1 Schematic for water addition to study water stress on maize seed

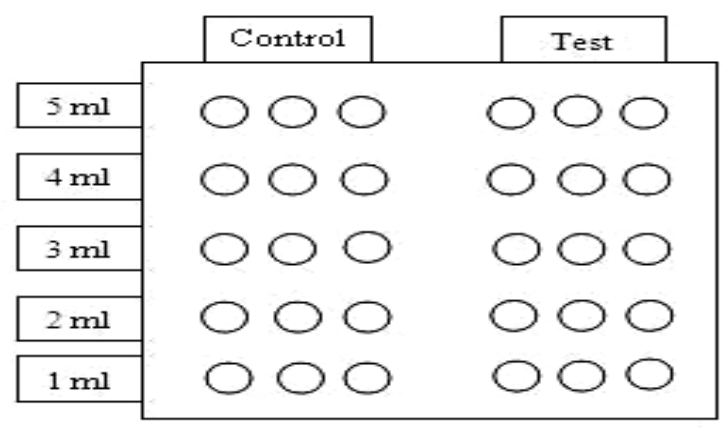

Fig.2a Frequency of isolated pathogens from urine $(n=177)$

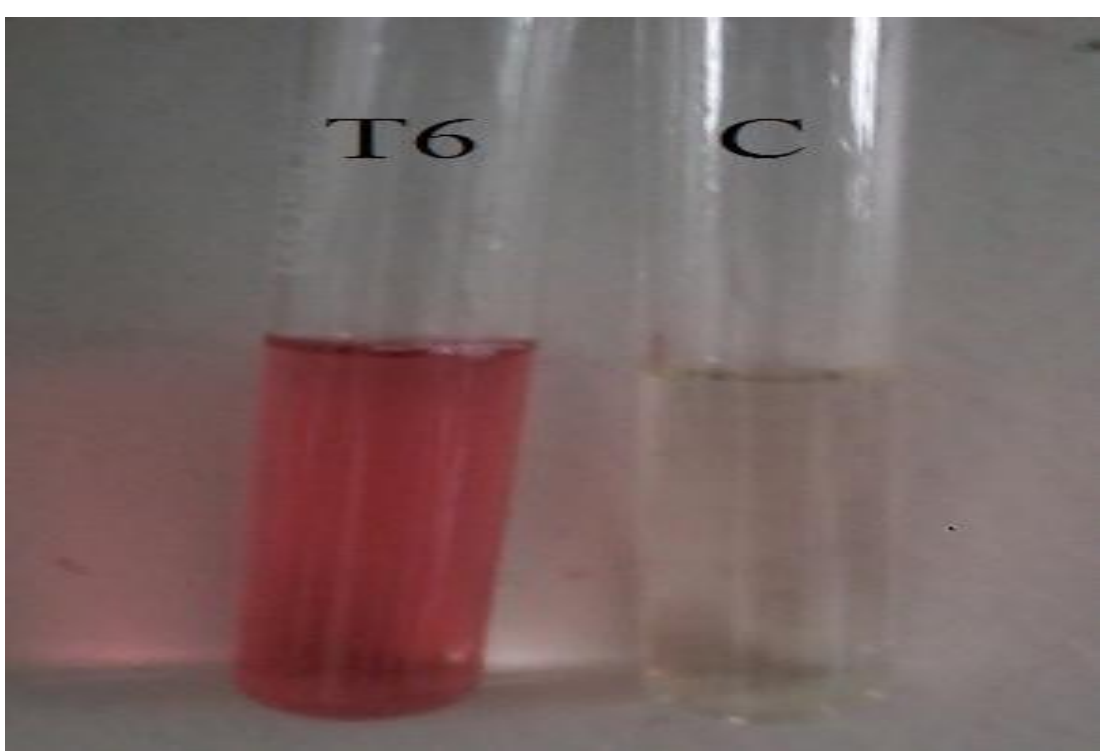


Fig.2b Production of HCN by Isolate SMJ2 II.

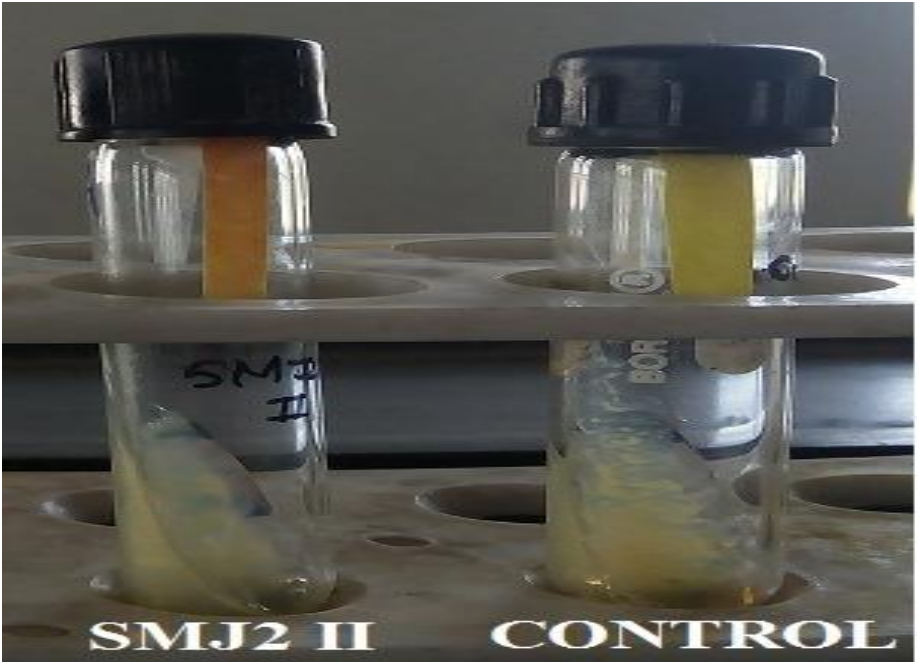

Fig.2c Production of ACC deaminase by Isolate T6

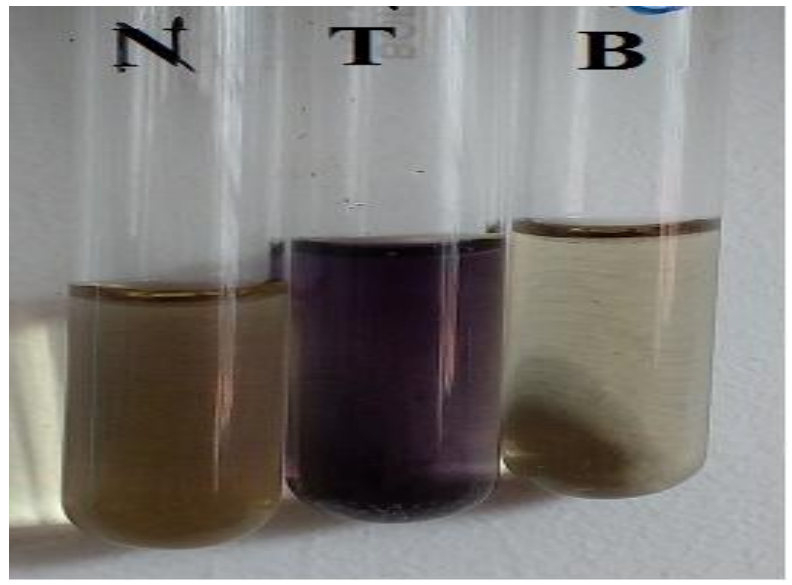

Fig.2d Maize seed root shoot elongation after 3 days of incubation i) consortium-RL treated ii) Control

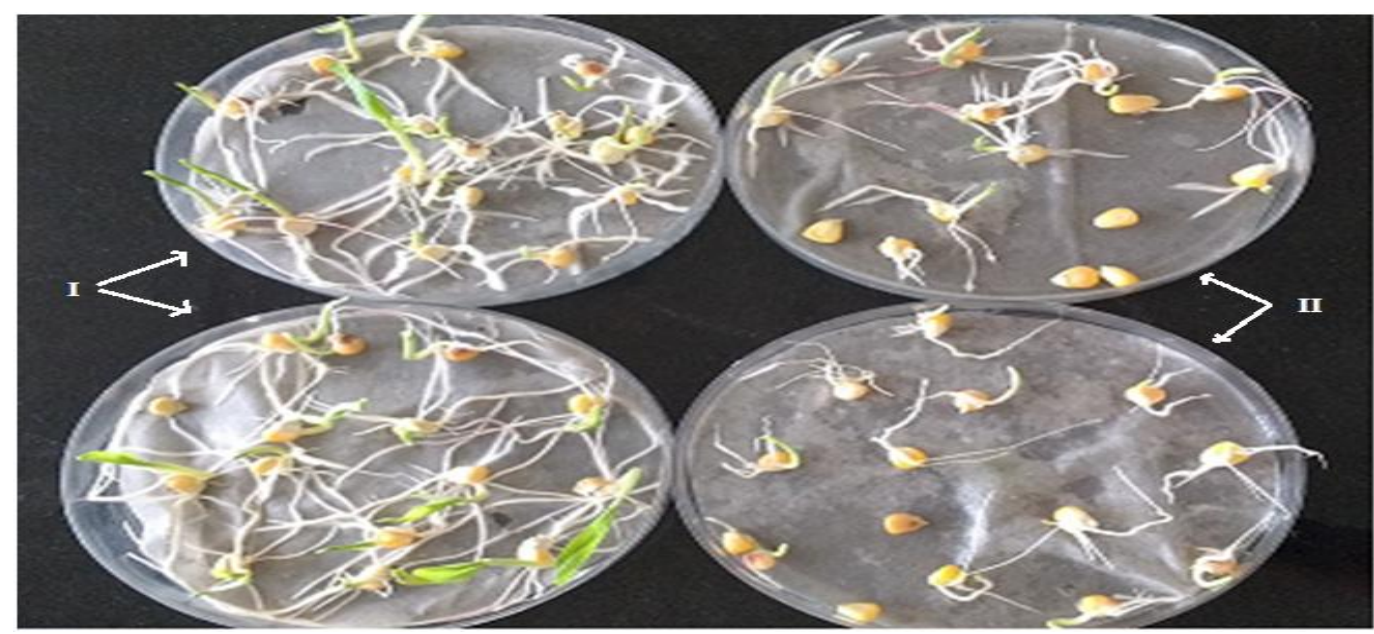


The research hypothesis formulated was that the mean root and shoots lengths of control seed was less than root and shoot lengths of consortium-RL treated seeds. The one tailed (left) test was used for data analysis and revealed that lengths (root and shoot) of consortium-RL treated seeds were significantly higher than control. The water stress factor revealed that consortium-RL treated seeds showed significant increase over comparable control. The consortiumRL offered protection against water stress compared to control possibly due to various PGPR mechanisms. One notable PGPR trait i.e. ACC deaminase production may play significant role in this water stress condition on maize plant. Comparable studies by Noumavo et al., (2013) reported the promoter effect of rhizobacteria (A. lipoferum, $P$. fluorescens, $P$. putida) on germination and the plants growth of maize in plate assay.

In conclusion, PGPR can be considered as sustainable alternative to chemical fertilizers to promote seed germination, biomass and crop yield. The hunt for efficient PGPR was attempted in this project resulting in 10 isolate exhibiting multiple PGP activities. The present study should serve as benchmark for advanced study on consortium-RL.

\section{Acknowledgments}

The author wishes to thank to Dr. B.D. Bhole, Head Department of Microbiology, Abasaheb Garware College, Pune for his encouragement and critical remarks during project work.

\section{References}

Agrawal, P.K.D., and Agrawal, S. 2013. Characterization of Bacillus sp. strains isolated from rhizosphere of tomato plants (Lycopersicon esculentum) for their use as potential plant growth promoting rhizobacteria. Int. J. Curr. Microbiol. App. Sci., 2(10): 406-417.

Barriuso, J., B.R. Solano and Gutierrez Manero, F. 2008. Protection against pathogen and salt stress by four plant growth promoting rhizobacteria isolated from Pinus sp. on Arabidopsis thaliana. Phytopathol., 98(6): 666672.

Berg, G. 2009. Plant-microbe interactions promoting plant growth and health: Perspectives for controlled use of microorganisms in agriculture. Appl. Microbiol. Biotechnol., 84: 11-18.

Bharucha, U.D., K.C. Patel, and Trivedi, U.B. 2013. In vitro screening of isolates for its plant growth promoting activities from the rhizosphere of Alfalfa (Medicago sativa). J. Microbiol. Biotech. Res., 3(5): 79-88.

Bhatt, P.V., and Vyas B.R.M. 2014. Screening and Characterization of Plant Growth and Health Promoting Rhizobacteria. Int. J. Curr. Microbiol. App. Sci., 3(6): 139-155.

Brick, J.M., R.M. Bostock, and Silverstone S.E. 1991. Rapid in-situ assay for indole acetic acid production by bacteria immobilized on nitrocellulose membrane. Appl. Environ. Microbiol., 57: 535-538.

Cappuccino, J. C., and Sherman, N.1992. In: Microbiology: A Laboratory Manual, New York, pp. 125-179.

Castric, P.A. 1975. Hydrogen cyanide, a secondary metabolite of Psuedomonas aeruginosa. Can. J. Microbiol., 21: 613-618.

Dimkpa, C., T. Weinand, and Asch, F. 2009. Plant Rhizobacteria Interactions Alleviate Abiotic Stress Conditions. Plant, Cell and Environ., 32(12): 1682-1694.

Gao, J.P., D.Y. Chao, and Lin, H. 2007. 
Understanding abiotic stress tolerance mechanisms: Recent studies on stress response in rice. J. Integr. Plant Biol., 49(6): 742-750.

Glick, B.R. 2014. Bacteria with ACC deaminase can promote plant growth and help to feed the world. Microbiol. Res., 169(1): 30-39.

Goteti, P.K., L.D.A. Emmanuel, S. Desai, and Shaik, M.H. A. 2013. Prospective Zinc Solubilising Bacteria for Enhanced Nutrient Uptake and Growth Promotion in Maize (Zea mays L.). Int. J. Microbiol., 869697 10.1155/2013/869697.

Joseph, B., Patra, R.R., and Lawrence, R. 2007. Characterization of plant growth promoting Rhizobacteria associated with chickpea (Cicer arietinum L). Int. J. Plant Prod., 1(2): 141-152.

Kloepper, J.W., and Schroth, M.N. 1978. Plant growth promoting rhizobacteria on radishes. In Station de pathologie vegetable et phyto-bacteriologie (ed.), Proceedings of the $4^{\text {th }}$ International Conference on Plant Pathogenic Bacteria, vol. II. Gilbert- Clarey, Tours, France, 879-882.

Kumar, A., A, Prakash, and Johri, B. 2011. Bacillus as PGPR in Crop Ecosystem. In: Maheshwari, D. K. (ed.) Bacteria in Agrobiology: Crop Ecosystems. Springer Berlin Heidelberg.

Lai, W.A., Peter Kämpfer, A.B. Arun, F.T. Shen, B.Huber, P.D. Rekha, and Young, C.C. 2006. Deinococcus Ficus Sp. Nov., Isolated from the Rhizosphere of Ficus Religiosa L. Int. J. Systematic And Evol. Microbiol., 56(4): 787-91.

Lichtenthaler, H.K. 1996. Vegetation stress: An introduction to the stress concept in plants. J. Plant. Physiol., 148(1/2): 4-14.

Nimnoi, P., and Pongsilp, N. 2009. Genetic diversity and plant growth-promoting ability of the indole-3-acetic acid (IAA) synthetic bacteria isolated from agricultural soils as well as rhizosphere, rhizoplane and root tissue of Ficus religiosa L., Leucaena leucocephala and Piper sarmentosum Roxb. Res. J. Agri. Biol. Sci., 5(1): 2941.

Noumavo, P.A., E. Kochoni, Y.O. Didagbe, A. Adjanohoun, M. Allagbe, R. Sikirou, and Gachomo, E.W. 2013. Effect of different plant growth promoting rhizobacteria on Maize seed germination and seedling development. American J. Plant Sci., 4(5): 1013-1021.

Parmar, P., and Sindhu, S. 2013. Potassium Solubilization by Rhizosphere Bacteria: Influence of Nutritional and Environmental Conditions. J. Microbiol. Res., 3(1): 25-31.

Penrose, D.M., and Glick, B.R. 2003. Methods for isolating and characterizing ACC deaminase containing plant growth promoting rhizobacteria. Physiologia Plantarum, 118(1): 10-15.

Planchamp, C., G. Glauser, and MauchMani, B. 2014. Root inoculation with Pseudomonas putida KT2440 induces transcriptional and metabolic changes and systemic resistance in maize plants. Front Plant Sci., 5: 719.

Reetha, A.K., S.L. Pavani, and Mohan, S. 2014. Hydrogen cyanide production ability by bacterial antagonist and their antibiotics inhibition potential on Macrophomina Phaseolina (Tassi.) Goid. Int. J. Curr. Microbiol. App. Sci., 3(5): 172-178.

Schwyn, B., and Neilands, J. 1987. Universal chemical assay for the detection and determination of siderophores. Anal. Biochem., 160: 4756.

Vinocur, B., and Altman, A. 2005. Recent 
advances in engineering plant tolerance to abiotic stress: achievements and limitation. Curr. Opin. Biotech., 16(2): 123-132.

Wahid, A., S. Gelani, M. Ashraf, and Foolad, M. 2007. Heat tolerance in plants: an overview. Environ. Exp. Bot., 61(3):199-223.

Yang, J., J.W. Kloepper, and Ryu, C.M. 2009. Rhizosphere bacteria help plants tolerate abiotic stress. Trends Plant
Sci., 14(1): 1-4.

Zaidi, A., M.S. Khan, M. Ahemad, M. Oves, and Wani, P.A. 2009. Recent Advances in Plant Growth Promotion by Phosphate-Solubilizing Microbes.In: Khan MS et al (Eds) Microbial Strategies for Crop Improvement. Springer-Verlag, Berlin Heidelberg. Pp.2350.

\section{How to cite this article:}

Seema P. Rodge, Sayali K. Sable, Shraddha K. Salve, Sujata A. Sawant and Niranjan Prakashrao Patil. 2016. Isolation and Characterization of PGPR from Roots of Ficus religiosa growing on Concrete Walls and its Effect on Plant Growth in Drought Condition. Int.J.Curr.Microbiol.App.Sci. 5(9): 583-593. doi: http://dx.doi.org/10.20546/ijcmas.2016.509.066 